\title{
COMPARATIVE EVALUATION OF TACROLIMUS 0.03\% OINTMENT VS OLOPATADINE 0.2\% EYE DROPS IN THE TREATMENT OF VERNAL KERATOCONJUNCTIVITIS
}

\author{
Hassan Sajjad Rathore, Shahzad Saeed, M. Ahsan Mukhtar, Umar Ijaz, Asad Habib*, Iqra Ghaus \\ Combined Military Hospital Quetta/National University of Medical Sciences (NUMS) Pakistan, *Pakistan Naval Ship, Shifa Hospital, \\ Karachi/National University of Medical Sciences (NUMS) Pakistan
}

\begin{abstract}
Objective: To compare the efficacy of tacrolimus $0.03 \%$ ointment to olopatadine $0.2 \%$ eye drops in the treatment of vernal keratoconjunctivitis.

Study Design: Prospective cross-sectional study.

Place and Duration of Study: Eye Department Combined Military Hospital Quetta, from Feb to Jul 2019.

Methodology: A total of 69 patients with active vernal keratoconjunctivitis (VKC) were included in this study. Thirty six $(52.17 \%)$ patients were randomized in tacrolimus group and $33(47.83 \%)$ in olopatadine group B. Baseline values of the subjective symptom score (SSS) and the objective sign score (OSS) were noted. Patients were reviewed on weeks 2, 4, 8 and 12 and the scores at each visit were summed. These scores were used for comparison between groups.

Results: At the start of the study, the mean subjective symptoms score and objective sign score of group A was 9.0 \pm 2.04 and $3.93 \pm 1.93$ respectively, while that of group B was $8.88 \pm 2.18$ and $4.36 \pm 1.90$ respectively. At the end of 12-weeks, the mean subjective symptoms score and objective sign score of group A reduced to $0.11 \pm 0.32$ and 0.08 \pm 0.28 respectively, while that of group B reduced to $1.70 \pm 0.77$ and $0.64 \pm 0.55$ respectively. Total improvement of scores (as a percentage of baselines) among tacrolimus group was $98.3 \%$ and olopatadine group was $83 \%$.

Conclusion: Although both $0.03 \%$ tacrolimus and $0.2 \%$ olopatadine were effective in improving the signs and symptoms of VKC, $0.03 \%$ tacrolimus was significantly superior.
\end{abstract}

Keywords: Olopatadine, Tacrolimus, Vernal keratoconjunctivitis.

This is an Open Access article distributed under the terms of the Creative Commons Attribution License (http://creativecommons.org/licenses/by/4.0), which permits unrestricted use, distribution, and reproduction in any medium, provided the original work is properly cited.

\section{INTRODUCTION}

Vernal keratoconjunctivitis (VKC) is a sightthreatening chronic inflammatory eye disease frequently seen in children and young adults. It usually starts after 5 years of age and persists for 2-10 years $^{1}$, resolving by puberty though it may start earlier and continue well into adulthood. Maleto-female ratio in this disease is approximately $2: 1^{1}$. The disease is seen mainly in tropical climate such as in countries surrounding the Indian subcontinent, the Middle-East, the Mediterranean, in West African nations and in Japan ${ }^{2}$. The prevalence of VKC in tropical regions may be up to $5 \%{ }^{3}$. Although the name vernal gives the impression of a seasonal manifestation, frequently this allergic disease continues throughout the year.

Correspondence: Dr Hassan Sajjad Rathore, Resident Ophthalmology, Combined Military Hospital, Quetta Pakistan

Received: 07 Sep 2019; revised received: 12 Jan 2020; accepted: 20 Jan 2020
The patients may experience different phases because of fluctuation of inflammatory process of the disease, and these may result in decreased quality of life and permanent corneal injury ${ }^{4,5}$. Patients are visually handicapped because of severe itching along with lacrimation, a mucoid discharge, photophobia, burning and heaviness of eyelids due to involvement of the tarsal conjunctiva $^{6}$. Conjunctival signs include hyperemia, diffuse fine papillary hypertrophy, macropapillae, giant cobblestone tarsal papillae in some variants and limbal papillae with Horner-Trantas dots.

Previously considered solely an IgE mediated disease, recent insight into VKC and culture results from conjunctival scrapings reveal a multifaceted pathogenesis with a pronounced role of Th2 lymphocytes along with mast cells, eosinophils, basophils, plasma cells and macrophages $^{7}$. Papillary reaction and tissue remodeling on 
the tarsal conjunctiva of patients are mediated by IL-4, IL-5, IL-13 plus other growth factors and cytokines released from Th2 cells ${ }^{8}$.

Currently, olopatadine is one of the most commonly prescribed antihistamine for allergic conjunctivitis ${ }^{9}$. Tacrolimus, on the other hand, is an immunosuppressive drug, which is now increasingly being used as a steroid sparing treatment option in VKC. Several studies were carried out to assess the role of tacrolimus for VKC, however, in our search of various research databases, we could not find any study comparing the efficacy of tacrolimus vs olopatadine (both these drugs are being used for providing long-term symptomatic relief for VKC patients). Moreover, most of the studies done on tacrolimus evaluated the effect of comparatively high concentration of the drug (topical tacrolimus $0.1 \%)^{10-12}$. The use of such high-dose topical tacrolimus was accompanied by frequent burning sensation and irritation.

In Pakistan, a large number of cases of VKC have been reported, especially in the dry arid climatic region of eastern and western Balochis$\tan ^{13}$. Extreme heat, dryness and dust storms are the main features of this climatic zone. With the rise of global warming in the last two decades, this region has seen a surge in external eye diseases, especially VKC. Hot dry weather along with dust exposure are the main reasons behind this rise, as they are positively associated with VKC and other external eye diseases ${ }^{14}$. This was the rationale of conducting this research in Quetta, the capital of Balochistan, Pakistan. As ophthalmic preparation of tacrolimus is not available in Pakistan, we used the lowest available concentration of tacrolimus skin ointment i.e, $0.03 \%$.

\section{METHODOLOGY}

All of the VKC patients presenting to the Eye Department Combined Military Hospital, Quetta from February 2019 to July 2019, were recruited into this prospective cross-sectional study. VKC was diagnosed clinically by consultant ophthalmologists, according to the generally accepted criteria $^{15}$. Patients were selected through universal sampling, irrespective of the age, gender, ethnicity and residence. Only the patients having active disease at the time of enrollment were included in the study. A comprehensive history and thorough examination were used to exclude the presence of co-existing ocular diseases such as glaucoma, uveitis, ocular infection, corneal disease and systemic diseases like diabetes and hypertension. Co-existing asthma, allergic rhinitis and atopic dermatitis were not included in the exclusion criteria. The study proposal was approved by the Ethics Committee of the Combined Military Hospital, Quetta (IERB approval no. Ext-2305/READ-IRB/001).

A complete ophthalmologic examination of the eligible patients was done including scoring designed specifically for VKC. Ophthalmologic and oral anti-allergic drugs were discontinued for 2-weeks (run-in period). Rescue measures comprised only of a 3-day short course of topical steroids and cold compresses.

Week 0: Patients were called to the eye OPD after the run-in period for another complete ophthalmological examination including unaided visual acuities, Goldmann tonometry, slit lamp bio-microscopy for grading severity of conjunctival hyperemia, chemosis, size and number of papillae, corneal involvement and number of limbal papillae. Patients were then randomly divided into 2 groups.

Block randomization was done using online research randomizer. Thirty six $(52.17 \%)$ out of the 69 patients were assigned to group $\mathrm{A}$ and the remaining 33 (47.83\%) were assigned to group B according to generated random allocation sequence. Patients in group A were given a $10 \mathrm{gm}$ tube of $0.03 \%$ tacrolimus ointment while patients in group B received $0.2 \%$ olopatadine eyedrops. A $0.5 \mathrm{~cm}$ column of the ointment was applied onto the lower conjunctival fornix of each eye. Both the eyedrops and the ointment were used twice daily. Baseline values of the subjective symptom score (SSS) and the objective sign score (OSS) were noted.

Week 2, 4 and 8: patients were again asked to return to the eye OPD for complete ophthal- 
mologic examination. New values of the subjective and objective scores were recorded.

Week 12: patients returned for the last examination. Final readings of the scores were recorded. Each patient was seen by an ophthalmologist on every visit.

\section{Clinical Scoring System}

The main outcome measure was total subjective symptom scores and total objective ocular sign score at each visit (tables-I \& II). The scores at each visit were added. Maximal values of subjective symptoms and objective signs score were 15 and 12 respectively. Comparison between groups was done using these scores. while that of group B was $12.63 \pm 5.22$ years. Tarsal VKC was the most common type and limbal VKC the least common as shown in fig-1.

Mixed type had the highest subjective symptoms \& objective sign scores (means $=7.03 \pm 5.52$ and $8.38 \pm 2.91$ ) followed by tarsal type (means $=5.84 \pm 2.54$ and $7.52 \pm 2.14$ ) and limbal type (means $=5.36 \pm 3.72$ and $5.15 \pm 1.06$ ). The most common symptom reported by the patients was itching and least common was burning sensation (fig-2).

At the end of the 2-week (run-in) period, before starting the study, the mean subjective symptoms score and objective sign score of group A was $9.0 \pm 2.04$ and $3.93 \pm 1.93$ respectively,

Table-I: Subjective symptom scores.

\begin{tabular}{l|c|c|c|c}
\hline Symptoms & Grade 0 & Grade 1 & Grade 2 & Grade 3 \\
\hline Itching & & & & \\
$\begin{array}{l}\text { Photophobia } \\
\text { Tearing }\end{array}$ & $1-2$ times / day & $3-5$ times / day & $5-9$ times / day & $>10$ times / day \\
$\begin{array}{l}\text { Grittiness } \\
\text { Burning sensation }\end{array}$ & & & \\
\hline Total Score & & & \\
\hline
\end{tabular}

\begin{tabular}{l|c|c|c|c}
\hline \multicolumn{2}{l}{ Table-II: Objective ocular sign scores. } & Grade 2 & Grade 3 \\
\hline Signs & Grade 0 & Grade 1 \\
$\begin{array}{l}\text { Conjunctival } \\
\text { Injection }\end{array}$ & None & $\begin{array}{c}\text { Dilation of some } \\
\text { vessels }\end{array}$ & Dilation of many vessels & $\begin{array}{c}\text { Not able to distinguish } \\
\text { different blood vessels }\end{array}$ \\
\hline Limbitis & None & $\begin{array}{c}\text { 1-3 limbal } \\
\text { papillae }\end{array}$ & 4-6 limbal papillae & 7 or more limbal papillae \\
\hline $\begin{array}{l}\text { Corneal } \\
\text { Involvement }\end{array}$ & None & $\begin{array}{c}\text { Only a few } \\
\text { punctate erosions }\end{array}$ & Half cornea involved & $\begin{array}{c}\text { Diffusely scattered on whole } \\
\text { cornea }\end{array}$ \\
\hline Giant Papillae & None & $\begin{array}{c}\text { A few giant } \\
\text { papillae }\end{array}$ & $\begin{array}{c}\text { Giant papillae in less than } \\
\text { half of upper palpebral } \\
\text { conjunctiva }\end{array}$ & $\begin{array}{c}\text { Giant papillae in more than } \\
\text { half of upper palpebral } \\
\text { conjunctiva }\end{array}$ \\
\hline Total Score & \multicolumn{4}{c}{} \\
\hline
\end{tabular}

All data were analyzed by Statistical Package for the Social Sciences (SPSS) version 23. Independent sample t-test and one-way ANOVA were utilized for quantitative analysis. A $p$-value $\leq 0.05$ was considered to be significant.

\section{RESULTS}

Out of the total 69 patients, 54 (78.3\%) were males and $15(21.7 \%)$ were female. The mean age of patients in group A was $12.75 \pm 5.54$ years while that of group B was $8.88 \pm 2.18$ and $4.36 \pm$ 1.90 respectively. Therefore, the two groups were comparable in terms of age and severity of disease.

Reduction of subjective symptoms and objective signs score within group (compared to their baselines) became statistically significant at week 4 for tacrolimus and olopatadine groups. These reductions continued in both groups throughout the 12-week period (table-III). 
Total improvement of scores (as a percentage of baselines) among tacrolimus group was $98.3 \%$ and olopatadine group was $83 \%$. When both the

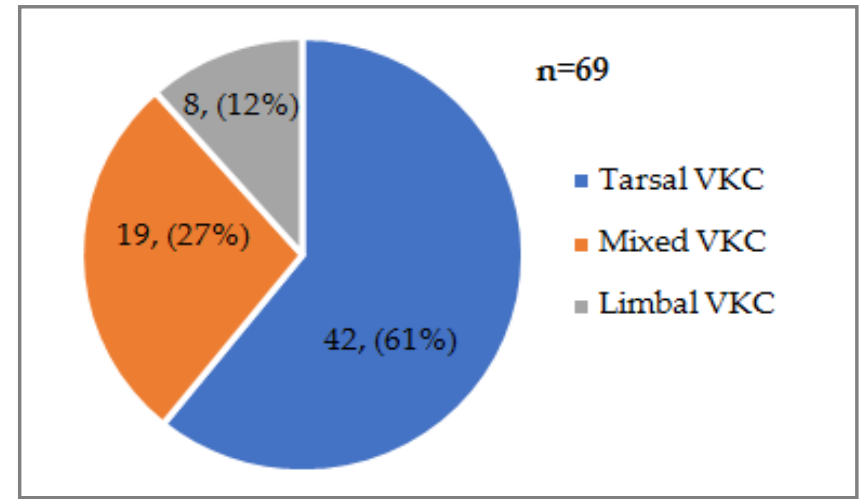

Figure-1: Frequency of types of VKC.

groups were compared with each other, the difference found was statistically significant (tableIV).

Although no major ocular complication or systemic side effects related to tacrolimus and olopatadine were noted, yet some patients in the tacrolimus group did complain of occasional pho- and dust etc., while surgical options involve removing upper tarsal giant papillae or debridement of non-healing shield ulcers; however, they are

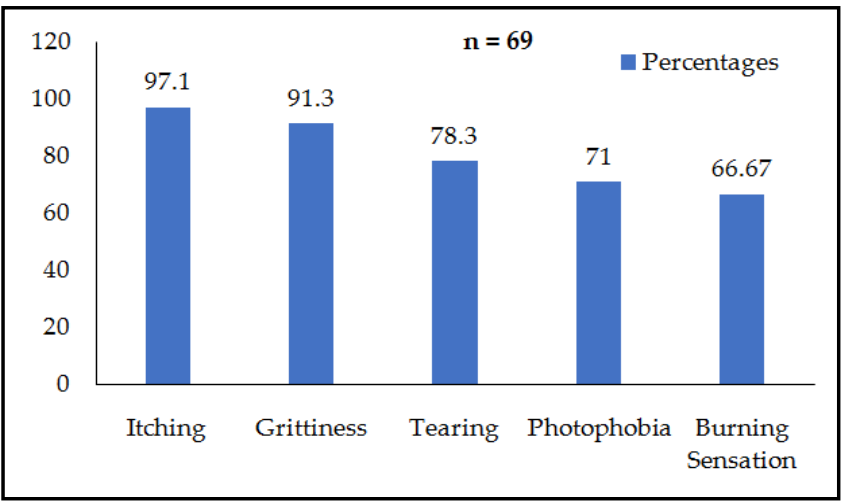

Figure-2: Frequency of symptoms.

reserved for severe cases. In the acute form of VKC, medical therapy is preferred. It includes topical antihistamines, mast cell stabilizers, mucolytics and lubricants as the first line of treatment. However, in the severe and chronic cases, topical corticosteroid drops and supratarsal steroid injections have to be added to control the

Table-III: Intra-group comparison of scores before \& after treatment.

\begin{tabular}{|c|c|c|c|c|c|c|}
\hline \multirow{2}{*}{ Group } & \multicolumn{2}{|c|}{ Mean Subjective Symptom Score } & \multirow{2}{*}{$p$-value } & \multicolumn{2}{|c|}{ Mean Objective Sign Score } & \multirow{2}{*}{$p$-value } \\
\hline & Week 0 & Week 12 & & Week 0 & Week 12 & \\
\hline $\begin{array}{l}\text { Tacrolimus } \\
(\mathrm{n}=36)\end{array}$ & $9.0 \pm 2.04$ & $0.11 \pm 0.32$ & $<0.001$ & $3.93 \pm 1.93$ & $0.08 \pm 0.28$ & $<0.001$ \\
\hline $\begin{array}{l}\text { Olopatadine } \\
(\mathrm{n}=33)\end{array}$ & $8.88 \pm 2.18$ & $1.70 \pm 0.77$ & $<0.001$ & $4.36 \pm 1.90$ & $0.64 \pm 0.55$ & $<0.001$ \\
\hline
\end{tabular}

Table-IV: Inter-group comparison of scores by oneway anova.

\begin{tabular}{l|c|c|c}
\hline Scores & $\begin{array}{c}\text { Tacrolimus } \\
(\mathbf{n}=\mathbf{3 6 )}\end{array}$ & $\begin{array}{c}\text { Olopatadine } \\
(\mathbf{n = 3 6 )}\end{array}$ & $p$-value \\
\hline Mean Subjective Symptom Score (Week 12) & $0.11 \pm 0.32$ & $1.70 \pm 0.77$ & $<0.001$ \\
\hline Mean ObjectiveSign Score (Week 12) & $0.08 \pm 0.28$ & $0.64 \pm 0.55$ & $<0.001$ \\
\hline
\end{tabular}

tophobia. No patient needed to terminate the medication because of severe adverse effects, however, $1(2.78 \%)$ patient in the tacrolimus group and $5(15.15 \%)$ in the olopatadine group required local steroids for 3 days to control extreme redness and itching.

\section{DISCUSSION}

Broadly, the treatment of VKC is divided into prevention, medical and surgical approaches. Preventive options include vaccination and avoiding allergens like house dust mites, pollen symptoms. Injudicious and prolong use of topical steroids may cause glaucoma, cataract, and secondary infections ${ }^{16}$. Children suffering from VKC are particularly at risk of developing steroidinduced complications, as they are the most commonly affected age group.

Currently, second-generation antiallergic drugs are the first-choice drugs to treat VKC, as they have both antihistaminic and mast-cell stabilizing activities. Olopatadine is one such medicine which acts as a selective antagonist of the 
histamine $\mathrm{H} 1$ receptor, thus inhibiting histamine release and stabilizing mast cells. Currently, it's the most commonly prescribed drug for allergic conjunctivitis along with topical steroids. It was approved by US Food and Drug Administration in $0.1 \%, 0.2 \%$ and $0.7 \%$ strengths for treating allergic conjunctivitis.

On the other hand, Tacrolimus is a strong, nonsteroidal, macrolide immunosuppressant isolated from Streptomyces tsukubaensis ${ }^{17}$, that is 100 times more potent than cyclosporine ${ }^{18}$. The mechanism of action of tacrolimus has not been fully understood as yet, however, it is thought to suppress Th2 lymphocyte activation(the key cells in $\mathrm{VKC}$ ), $\mathrm{T}$ helper cell-mediated B-cell proliferation, and formation of cytokines. In the beginning, it was used as an immuno-suppressant in liver transplants and then in other organ transplants ${ }^{19}$. Now, it is being used in the treatment of skin disorders such as vitiligo and atopic dermatitis etc. Both efficacy and safety of tacrolimus have been evaluated in different types and concentrations with different overall efficacy.

In this study, all the patients who received $0.03 \%$ tacrolimus, and those under treatment with $0.2 \%$ olopatadine had significant improvement, and the severity of their symptoms significantly decreased; so, both drugs are effective options for patients with VKC. However, difference between both drugs was also statistically significant, leading to the conclusion that tacrolimus group had fewer signs and symptoms remaining than the olopatadine group after 3 months of treatment.

Similar to this study, Sameera Irfan et al 20 , showed that topical use of $0.03 \%$ tacrolimus skin ointment was a safe and effective treatment for moderate to severe VKC; however, in contrast to our study, the cumulative percentage of improvement in signs and symptoms was $90.43 \%$ as compared to $98.3 \%$ in this study. This may be due to the difference of wheather in the location of both these studies. In another prospective doublemasked randomized comparative trial, Lab-charoenwongs et $a l^{1}$, showed that in children with active VKC, $0.1 \%$ tacrolimus eye ointment was effective after 4 weeks of treatment. Total improvement of symptoms (as a percentage of baselines) among tacrolimus group was $86.49 \%$, which was statistically significant $(p<0.01)$.

In another study, Vichyanond et al21, also used tacrolimus for treatment of severe VKC for a long-term period without significant adverse effects. Prolonged use of the drug tacrolimus showed reduction not only in symptoms but also in papillary hyperplasia. Muller et al22, performed a comparative study among 21 patients with severe VKC and found that addition of olopatadine to $0.03 \%$ tacrolimus would have no further effects. The scores for symptoms decreased between the assessments in both groups $(-1.7 \pm 3.9$ in the tacrolimus plus olopatadine group; $-0.6 \pm 1.6$ in the tacrolimus plus placebo group), with no significant difference between groups ( $p=0.205)$.

Although there are different studies on efficacy of tacrolimus in treatment of VKC, there is no comparative study on efficacy of tacrolimus versus olopatadine. Ours is the first study comparing both these drugs for treatment of VKC.

Various complications associated with tacrolimus have been recorded including reactivation of herpes simplex keratitis and increased susceptibility to molluscum contagiosum ${ }^{23}$. However, none of the patients in our study suffered from any serious ocular complication. Although this study has some limitations, like the lack of diversity in the sample size and the relatively short period of follow-up, the importance of our study lies in including both subjective and objective data in calculation of result of a relatively large sample size. However, we do need more studies with a long-term follow-up to confirm the safety and efficacy of this drug in the future.

\section{CONCLUSION}

In conclusion, our data indicates that although both these drugs are effective, tacrolimus $0.03 \%$ ointment is superior to olopatadine $0.2 \%$ eye drops in alleviating the symptoms and clinical signs of patients with VKC. 


\section{CONFLICT OF INTEREST}

This study has no conflict of interest to be declared by any author.

\section{REFERENCES}

1. Labcharoenwongs $\mathrm{P}$, Jirapongsananuruk $\mathrm{O}$, Visitsunthorn $\mathrm{N}$. Adouble-masked comparison of $0.1 \%$ tacrolimus ointment and $2 \%$ cyclosporine eye drops in the treatment of vernal kerato conjunctivitisin children. Asian Pac J Allergy Immunol 2012; 30(3): 177-84.

2. Collum MT. Vernal keratoconjunctivitis. Acta Ophthalmol Scand 1999; 228(Suppl): 14-16.

3. Bremond-Gignac D, Donadieu J, Leonardi A. Prevalence of vernalkeratoconjunctivitis: a rare disease?. Br J Ophthalmol 2008; 92(1): 1097-02.

4. Arif A, Aaqil B, Siddiqui A, Nazneen Z, Farooq U. Corneal complications and visual impairment in vernal keratoconjunctivitis patients. J Ayub Med Coll 2017; 29(1): 58-60.

5. Sultan S, Taqi U, Rizvi SZ, Ahmed T. The clinical presentation and frequency of ocular complications associated with vernal keratoconjunctivitis. Pak J Surg 2011; 27(2): 125-30.

6. Addis H, Jeng B. Vernal keratoconjunctivitis. Clinical Ophthalmol 2018; 12(1): 119-23.

7. Cook EB. Tear cytokines in acute and chronic ocular allergic inflammation. Curr Opin Allergy Clin Immunol 2004; 4(5): 441-45.

8. Vichyanond P, Pacharn P, Pleyer U, Leonardi A. Vernal keratoconjunctivitis: a severeallergic eye disease with remodeling changes. Pediatr Allergy Immunol 2014; 25(4): 314-22.

9. Rosenwasser LJ, O'Brien T, Weyne J, Lanny J. Mast cell stabilization and anti-histamine effects of olopatadine ophthalmic solution: a review of pre-clinical and clinical research. Current Medical Research and Opinion 2005; 21(9): 1377-87.

10. Liu FY, Liu HY, Chu HS, Chen WL, Hu FR, Wang IJ. Dermatologic Tacrolimus $0.1 \%$ Ointment on The Eyelids for SteroidRefractory Vernal Keratoconjunctivitis. Graefe's Archive for Clinical Experimental Ophthalmol 2019; 257(5): 967-74.

11. Nir E, Ben-Eli H, Solomon A. topical tacrolimus for allergic eye diseases. Current Opinion in Allergy and Clin Immunol 2019;
19(5): 535-43.

12. Samyukta, Sadasivan K. et al. Monotherapy of topical tacrolimus in the treatment of vernal keratoconjunctivitis in the pediatric population. J Amr assoc Pediatr Ophthalmol Strab 2019; 23(1): e1-e5.

13. Lakho KA, Jadoon MZ, Mahar PS. Pattern of Ocular Problems in School going Children of District Lasbela, Balochistan. Pak J Ophthalmol 2012; 28(4): 200-05.

14. Alemayehu, A, Yibekal B, Fekadu S. Prevalence of vernal keratoconjunctivitis and its associated factors among children in Gambella town, southwest Ethiopia, Public Lib of Sci One 2018; 14(4): p.e0215528-30.

15. Zicari A, Capata G, Nebbioso M, De Castro G, Midulla F, Leonardi L, et al. Vernal Keratoconjunctivitis: an update focused on clinical grading systemItal J Pediatr 2019; 45(1): 64-68.

16. Senthil S, Thakur M, Rao HL, Mohamed A, Jonnadula GB, Sangwan V, et al. Steroid-Induced Glaucoma and Blindness in Vernal Keratoconjunctivitis. Br J Ophthalmol 2020 104(2): 265-69.

17. William F. Review of medical physiology. $22^{\text {nd }}$ ed. Lange Medical Books; 2005. Ganong"s; [Internet]. http:// hdl.handle. net/ $123456789 / 425$.

18. Kumari R, Saha BC, Sinha BP, Mohan N. Tacrolimus versus cyclosporine- comparative evaluation as first line drug in vernal keratoconjunctivitis. Nepal J Ophthalmol 2017; 9(18): 128-35.

19. Peters DH, Fitton A, Plosker GL, Faulds D. Tacrolimus. A review of its pharmacology, and therapeutic potential in hepatic and renal transplantation. Drugs 1993; 46(2): 746-94.

20. Irfan S. To Study the Efficacy \& Safety of Tacrolimus Skin Cream, 0.03\%, in VKC. Pak J Ophthalmol 2015; 31(1): 15-22.

21. Vichyanond, P. Kosrirukvongs, P. Use of Cyclosporine A and Tacrolimus in Treatment of Vernal Keratoconjunctivitis. Current Allergy Asthma Report 2013; 13(3): 308-14.

22. Muller GG, Jose NK, de Castro RS. Topical tacrolimus $0.03 \%$ as soletherapy in vernal keratoconjunctivitis: a randomized double-maskedstudy. Eye Contact Lens 2014; 40(2): 79-83.

23. Zribi H, Descamps V, Hoang-Xuan T, Crickx B, Doan S. Dramatic improvement of atopic keratoconjunctivitis aftertopical treatment with tacrolimus ointment restricted to theeyelids. J Eur Acad Dermatol Venereol 2009; 23(4): 489-90. 